taxes, and nobody knows whether the carts were properly disinfected afterwards. Whereas, had the Prefecture of Police condescended to utilise the carts of the Prefecture of the Seine the removal of the contaminated bedding sc. could have been performed at no cost and at no risk. These incidents will suffice to illustrate the disastrous consequences that accrue from the existence of rival authorities concerned in one and the same question.

In the meanwhile the cholera continues its slow progress, though there are more cases than is generally known or admitted. Within the walls of Paris itself twenty-seven cases are officially reported between July 11 th and 15th. The proportion of deaths is of course not yet known, but in previous records it has been very high. So far, however, it is in the suburbs, and not in Paris itself, that the epidemic is -doing its worst. After the lesson received in 1884 it was natural to expect that the authorities would be well prepared to meet any other similar epidemics. Such is not the case. There are better means now for coping with the danger, but these are not well organised. Fortunately, the epidemic is developing itself so slowly that there has been time to make preparation; also there is the hope that it may not become general-it certainly does not seem to have taken root in Paris itself. The cases are scattered all over the town, just as might be expected if the source of contamination was outside and had been brought in accidentally. So far therefore this fact helps to strengthen the belief that the drinking of the Seine water is the principal cause, as persons may drink that water when in the outskirts of Paris for business or pleasure and then fall ill on returning to the city.

\section{THE NECESSITY OF RE-ESTABLISHINGTHE CONTAGIOUS DISEASES ACT IN INDIA.}

By SURgeon-General Sir Wm. Moore, K.C.I.E., Q.H.P.

ALTHOUGH much has been done during recent years to improve the condition and social surroundings of soldiers and sailors we have not yet reached that problematical social millennium in which moral force shall overcome animal instincts. So long as human beings are constituted as they are physiological laws will be obeyed by the very great majority of the inhabitants of this world. For a young man who cannot marry, and who cannot attain to that exalted moral standard required for the suppression of natural instincts, there are only two ways of satisfaction-the one leads to disorders of body and mind, the other to the fearful dangers of venereal disease. In England, before the Contagious Diseases Act was passed and applied to certain military stations, the annual loss to the army owing to invaliding of soldiers for venereal disease amounted to three regiments, or, in other words, to the loss of the services of the whole force then serving in the United Kingdom for three weeks. In the navy the daily loss by men on the sick-list was 386, equal to the complement of an ironclad. A Committee of the House of Commons reported in 1862: "The facts are so appalling that we feel it a duty to press on Government the necessity of at once grappling" with the matter. Hence the Contagious Diseases Act in England. In 1866 the working of the Act was inquired into by a Committee of the House of Lords, who reported : "Prostitution appears to have diminished, its worst feature to have softened and its physical evils to have abated." In 1869 a Committee of the House of Commons reported: "The Contagious Diseases Acts have both directly and indirectly promoted the objects of sanitary and municipal police." In 1870 a Royal Commission stated that the ratio of primary syphilis among the military at protected stations had fallen from 120 per 1000 to 54 , or more than one-half. The next Committee was composed of members of the House of Commons in 1879, who gave a table showing the amount of disease among newly registered women and those on the registers at nine military stations. The figures for the newly registered women are 40.2 ; for those on the register, 5.7 . Yet all this, and much more that might be mentioned, did not prevent a section of society in England maintaining a continuous agitation against the Contagious Diseases Act, culminating in the passing of Mr. Stansfeld's motion in 1883,

"That this House disapproves of the Contagions Diseases Act." As might be expected, the immediate result of the passing of Mr. Stansfeld's Act was diminution of the number of females examined and admitted into hospital and a large increase of syphilis in the army and navy. There was also a. large increase of men arriving in India on board the troopships with primary syphilis; but the House of Commons, not satisfied with the mischief done, insisted in 1888 on the abolition of the Contagious Diseases Act in India. The result is shown in the recently published report (for 1890) on the health of the army in India. Allowing for readmissions, it would appear that 500 out of every 1000 men are suffering from renereal disease. In 1890 the total number of admissions into hospital for various forms of venereal disease was 34,152 out of a total strength of 67,823 . The admissions per 1000 for the whole of India in 1890 were 504. In 1887, the last year of the working of the Contagious Diseases Act, the admissions were 361 per 1000 . As from that period up to the clate of the last return (1890) there was an annual increase, so doubtless there has been a similar increase to the present time. We may therefore now conclude that nearly 600 per 1000 will be admitted during the year 1892 for venereal disease. In former days ague or some other tropical malady headed the lists of admissions and invaliding. Now the first place has been either usurped or nearly approached by venereal disease. For instance, in the Bombay Army in 1890 venereal disease caused 37 per cent. of the total sickness and ague 21 per cent. of the European Army in India during 1890 it is reported that 87 per 1000 were constantly sick, against 60 per 1000 in the ten years 1870-79, and much of this increased sickness must be attributed directly or indirectly to venereal disease.

The folly of what has been done is only equalled by the absurdity of the arguments which caused it to be done. The opponents of the Contagious Diseases Act object that, as the fear of contracting disease tends to prevent men yielding to vice, it is improper to prevent such disease; that the Contagious Diseases Act increases vice by rendering it safe; that reducing the penalties of wrongdoers is playing into the hands of transgressors. But if fear of disease prevented vice, it would not prevail so extensively as it does, in London for instance, where the Act has never been applied. None but medical men fully understand the dangers of syphilis, and what is generally known is not sufficient to act as a deterrent. Moreover, the disease of soldiers and sailors is as often as not contracted when the mind is obscured by alcohol. The opponents object that examination exerts a deteriorating influence on the women. But for confirmed prostitutes no further debasement is possible. Registration and the fact of the women coming to be examined effectually prevent what used to be common enough in Bombay at least-viz., girls being practically prisoners in brothels. All are brought to light and liberty. It is also objected that the women so dislike being examined that they will not submit unless compelled to do so. Well, when the Contagious Diseases Act was abolished in Bombay and the various examination offices closed, the women went about asking where the ${ }^{i}$ were to be examined. It is also asserted that the system is unjust to women, being directed against one sex for the benefit of the other. It is only directed against those of the one sex who are dangerous to themselves and men. The liberty of the subject has been made an opposing point; but no person has a right to spread a contagious disease. The opponents assert that the Act does no good. Now, although the results of the working of the rules for the prevention of venereal disease for the whole of India have not been so satisfactory as could be desired, the experience of certain stations where the rules have been carefully administered shows beyond all question that with proper management a most decided impression may be made on the prevalence of primary venereal disease. - I have no time to demonstrate this, but I know from experience that if the Contagious Diseases Act were well worked the amount of local syphilis may be reduced almost to nil. ' And it cannot be doubted that the care taken of diseased females must have tended to lessen venereal disease. When, as was the case in Bombay, from sixty to eighty diseased women were in the hospital who would otherwise be disseminating syphilis, such disease must be lessened. Whether the Act did any good or not, I think it is now tolerably certain that its abolition has done a great deal of harm. The opponents say that attendance at hospital should be voluntary. But women of the class will not voluntarily go into hospital confinement, but continue to ply their trade--some knowingly, others unknowingly--long after they are diseased. Perhaps the most absurd argument of the opponents is that syphilis 
is not the destructive malady it has been asserted to be. This impression appears to arise from the fact that, except in a few cases, syphilis is not a directly fatal disease such as cholera or bad forms of fever. It is indirectly and remotely that syphilis proves so destructive, and this is not appreciated. The opponents of the Contagious Diseases Act will not believe when they are told that eye diseases, affections of the spinal cord, of the brain, of the heart, and of the bloodressels result from syphilis, although such affections may be otherwise named. Neither will they believe that in India much of the cachexia, liver disease and fever from which the European soldiery especially suffer, is either purely syphilitic or much aggravated by syphilis, or that when an attack of sunstroke occurs it is much more likely to end in permanent disability if there is a syphilitic taint. It is also useless telling the opponents of the Contagious Diseases Act of inherited syphilis ; but any large hospital, whether in England or India, daily presents numbers of children the subjects of one or other of the forms of inherited venereal disease. The advantages which arose from the Contagious Diseases Act may be mentioned as diminution of severity of disease, prevention of disease, cure of disease, social improvement by a reduction in the number of brothels and the lessening of juvenile prostitution, and opportunities afforded to women for reformation. Having had the control of the Contagious Diseases Act in Bombay for some years when surgeon-general there, I know that such advantages did, to a greater or lesser extent, accrue from the working of the Act.

I regard the abolition of the Contagious Diseases Act in India as a display of igmorance almost unparalleled.

would ask how much longer is the health of the Anglo Indian Army to be undermined at the instance of agitators? Let us hope the Indian Army will not be called upon for service in the field while in its present deplorable condition.

\section{SOME MODES OF THERMAL TREATMENT AT STRATHPEFFER SPA.}

\section{By Fortescue Fox, M.D.Lond.}

A HIGH opinion of hot springs has been commonly held, even from the earliest times. The magnificent "Thermæ" or baths established by the Romans in Italy, Gaul and even Britain show how such waters were prized by them, first as a Iuxury and afterwards almost as a necessity of their civilisation. Subsequently larger and more definite claims were advanced as to the medicinal and even specific virtue of this and that bath in particular diseases-claims which have been countenanced by medical opinion even to the present day. of late years, however, an entire change of medical doctrine has taken place, arising from a more exact knowledge of the limited power of absorption possessed by the skin. Since it has been demonstrated that the sulphates and carbonates and even the chlorides and sulphides are not absorbed from their solutions by an unbroken skin, it has not been possible to believe that baths containing one or more of these ingredients possessed on that account any specific medicinal value. Therr potency, which is acknowledged, is rather of a general kind, depending on the thermal qualities in which they agree and not on the chemical qualities in which they differ. It is, however, possible that this doctrine may be pushed too far, if, for example, it is denied that chemical agencies may be competent to produce effects, stimulant or sedative, on the peripheral nerve-endings and circulation independently of absorption, or that in morbid states of the skin-eczema and ulcers, e.g.-absorption of such ingredients mar take place.

The internal use of the hot spring, relying as it does on the far more active absorptive power of mucous membrane, is not likely to be challenged or regarded as "indifferent"; but in

1 "In the estimate of baths therefore we may set aside the amount they contain of iron, lime, the sulphates of soda and magnesia, soda, iodine, bromine and arsenic; and as special baths we have only to consider those containing carbonic acid-the sulphur baths, the soo baths, the clinical effect of which is established and explained in a mechanically chemical manner; the moor baths (peat baths), in which special chemical agents are added to the general thermal effect; and sea baths."-Curative Effects of Baths and Waters : Braun, English Edition, p. 193 respect to their external use in the form of baths, most, if not all, of the warm mineral waters must be now regarded simply as thermal agencies The continuous baths of Leuk, the warm piscines of the Pyrenean spas, the thermal baths and douches of Aix-les-Bains and of Bath in England cannot any longer be held to depend for efficacy on their minute and varions mineralisation, but on the skilled and systematic application of warmth and moisture. "The old theory that "natural " or telluric heat was of a different quality from artificial heat and imparted thereby a special quality to thermal waters has no foundation in ascertained fact. It should also be observed that thermal treatment, properly so-called, includes not only the use of water and watery vapour naturally or artificially heated to the proper temperature, but also local forms, such as poultices and fomentations of every kind ; and in addition the application of heat without moisture, as in the Turkish bath, and locally, as the hot sand bath and the thermal hammer.

The following observations have reference to two forms of thermal treatment in use at Strathpeffer Spa, the douche bath in various shapes and the peat bath, in both of which the principal factor is the regulated application of moist heat.

1. The douche bath : This is largely used in the ordinary form of a jet or nozzle douche as an application to the affected joints in early rheumatoid arthritis and in some. cases of chronic rheumatism and gout. If serious disorganisation of the joints has not already taken place, perseverance in this treatment undoubtedly assists in restoring. to the parts a healthy nutrition, whether by its effect on the circulation or nervous supply it is impossible to say. It may be worth observing in this connexion that, next to the skin itself, the joints are the most superficial portions of the body and therefore the most amenable to external influences. If changes of temperature are competent, as is the case, to produce inflammatory conditions in susceptible joints, it is not unreasonable to attribute partly to the element of temperature the beneficial effects of the douche. The low-pressure donche so largely employed at Aixles-Bains, but until lately nowhere in this country, has been lately introduced at Strathpeffer. A large volume of water, almost without pressure and of a pleasant warmth, is continuously poured over the patient's back and shoulders whilst seated and whilst, it may be, the limbs are subjected to the ordinary (high pressure) douche. It is instructive to notice that enlightened medical opinion at the French spa is now inclined to allow that the strong hot douche is too "exciting" in many cases to which the gentle douche at lower temperatures is perfectly adapted and in which indeed it acts as a general nervous sedative. The spinal douche at Strathpeffer consists of fine jets of water in a vertical series, directed at close quarters upon the spine-the patient being comfortably seated-and given at a temperature ranging from $102^{\circ}$ to $115^{\circ}$. The apparatus admits of sudden alternations with cold where desirable. The whole body may meanwhile be subjected to a low pressure or rose douche at any desired heat. The spinal douche is principally used in neurasthenia, in sluggish circulation with cold extremities and particularly in cases of congestive and nervous dysmenorrhoea. It appears to act mainly through the vaso-motor system, both on the general circulation, causing warmth and flushing of the extremities, and probably in the same manner on the pelvic and abdominal organs. In numerous cases of dysmenorrhca the catamenia are reported as being quite painless after a course of these douches. Complete rest-lying down in an adjoining roomshould always follow a bath of this kind.

2. The peat bath (moor bath): This bath is composed of disintegrated peat, or moor earth, freed from extraneous. matter and mixed or churned with boiling water in a special apparatus separately for each bath. The peat itself is of a rich brown colour and is taken from deposits at an elevation of 1500 to 2000 feet. It is somewhat remarkable that this form of thermal treatment-for such in the main it un doubtedly is-although so prevalent and justly famous on the continent of Europe, was not apparently employed in this country until three years ago. It is held by competent autho. rities to be "less exciting" than other forms-that is to say, that it produces its effect at a lower temperature than other modes of thermal treatment. It is also further distingnished from most or all other baths by its consistence (that of a thin poultice), and especially by the state of chemical activity attributed to its ingredients. Among these ingredients, organic and inorganic, when freshly prepared at a high. temperature for the bath, it is believed that chemical trans- 